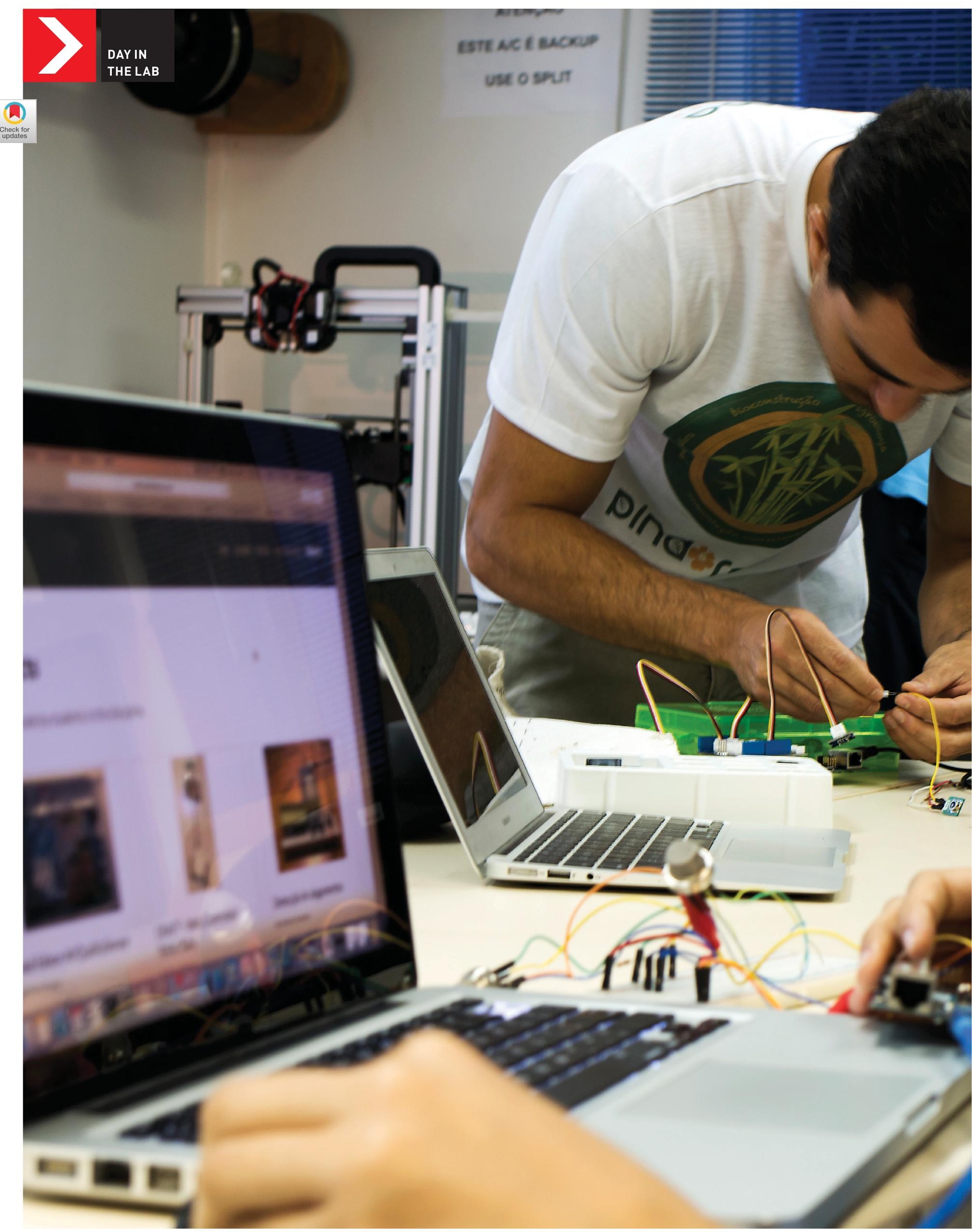




\section{SecondLab, PUC-Rio}

As told by Hugo Fuks, Marcio Cunha,

Bruno Chagas, Fernando Ismério, and Bruno Pontes

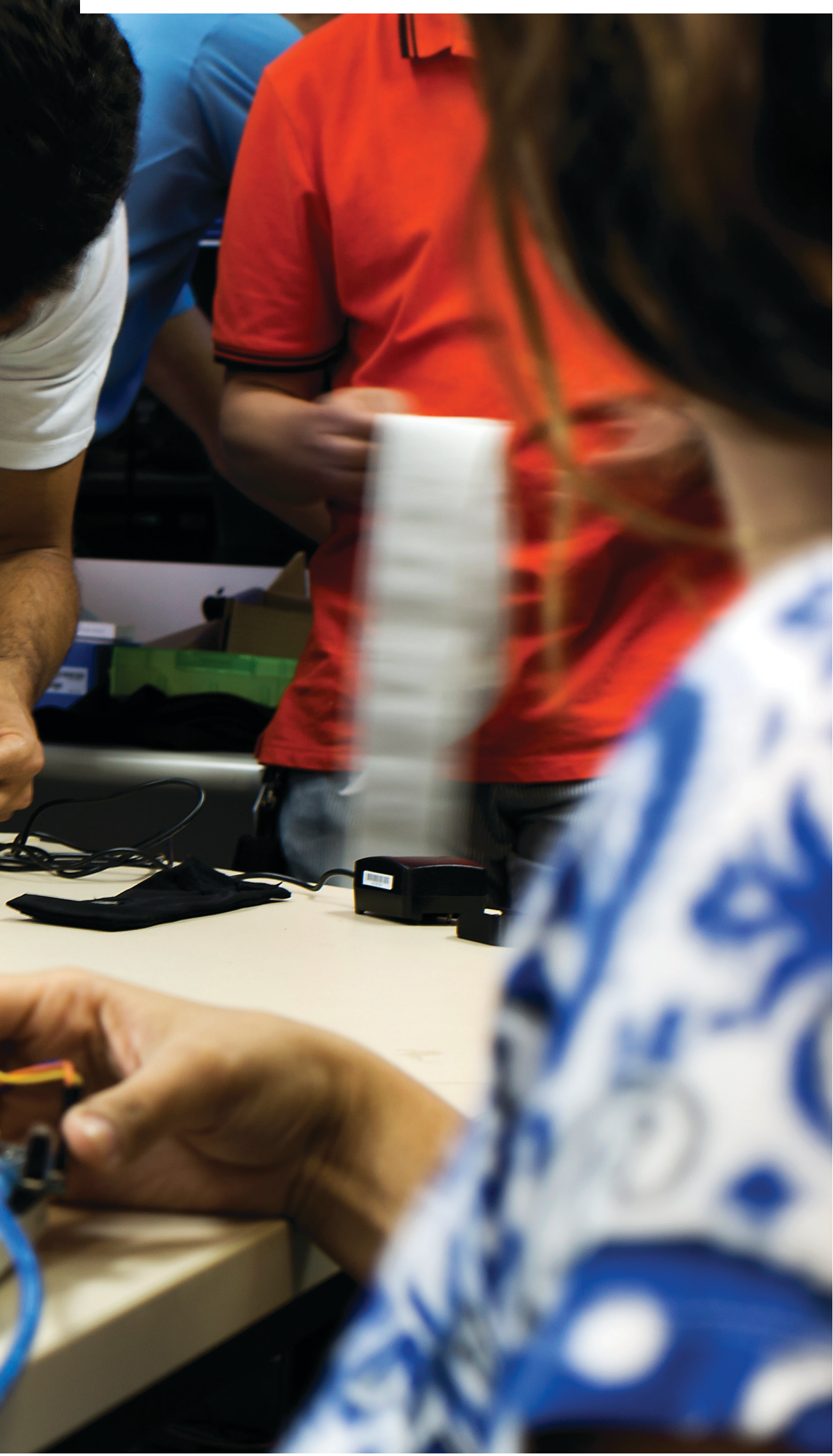

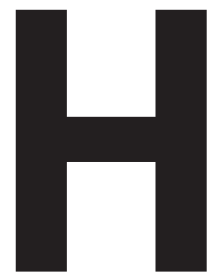

ow do you describe your lab to visitors? SecondLab is a branch of the Software

Engineering Lab at PUC-Rio (Pontifical Catholic University

of Rio de Janeiro) for prototyping assistive technology solutions based on software and novel hardware. Some of the research topics currently being investigated include the Internet of Things, wearables, sensing, and interacting in ubiquitous computing environments. We are concerned with applications and issues related to how these technologies can improve the lives of disabled, elderly, and convalescent persons.

\section{What is a unique feature of your lab?} SecondLab is an encouraging place for exploring computing beyond traditional desktop computers, targeting screenless devices and multimodal interface solutions. Our focus combines a strong prototyping approach with participatory design (at least we try doing it). We think our unique feature is using this mindset to approach real-world problems. Based on this approach, we created novel concepts such as Beauty Technology and Hairware.

How many people are in the lab, and what is the mix of backgrounds and roles? Currently there are five computing researchers working at the lab daily, but a larger group uses our space when the lab is used for teaching. We regularly interact with researchers from other departments on specific projects, such as when we worked closely with an industrial designer to prototype wearables to encourage body movement in cognitively impaired persons in a therapeutic environment. Everybody is responsible for keeping the space organized. Once in a while, a task force is assembled to ensure a minimum level of cleanliness and organization and to recycle used components and materials.

\section{Briefly describe a day in the life of} your lab. Usually loads of sharing takes place, as we exchange information on scientific papers, technological innovations, and media announcements that cross our topics of research. This 

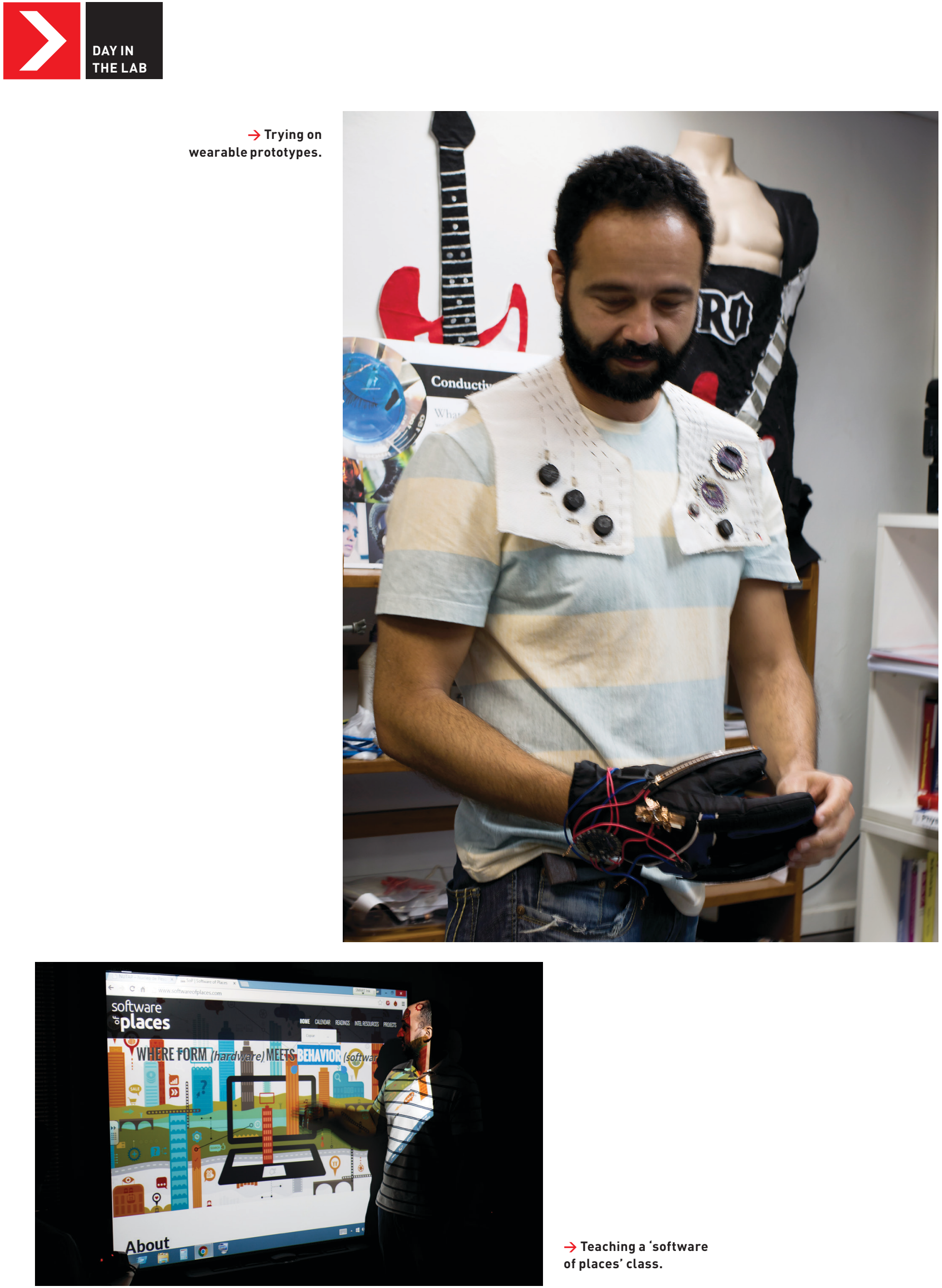

$\rightarrow$ Teaching a 'software

of places' class. 
